\title{
Utilización del reservorio continente de indiana en la patología del tracto urinario inferior
}

\author{
Augusto Gómez P.*; Antonio Redondo F.**; Carmen P. de Redondo***; Alberto Galvis C.; Luis E. Imbett B.****
}

RESUMEN: El presente artículo revisa los resultados de la aplicación de la Técnica Quirúrgica de Indiana, en 4 pacientes con daño total o parcial de vejiga causados: por cáncer vesical, 1 por parto distósico y 1 posthisterectomía total.

Las dos pacientes con fístulas uretrovesicovaginales, cloaca, consultaron por salida permanente de orina por genitales externos. Su edad media fue de 22 años y estrato socioeconómico bajo.

La prueba del colorante fue positiva en ambas y la cistoscopia confirmó la presencia de fístula uretrovesicovaginal extensa con gran pérdida de tejido vaginal y vesical.

La técnica aplicada fue la de Bolsa Continente de Indiana. La morbilidad en postoperatorio inmediato y tardío fue poco significativa y se resolvió satisfactoriamente. La mortalidad (1 caso) no fue inherente a la cirugía. (Invasión tumoral de Ca. de vejiga).

PALABRAS CLAVES: Incontinencia urinaria, cloaca, bolsa de Kock, bolsa de Mainz, reservorio continente de Indiana.

SUMMARY: This article reviews the results of Indiana's Surgery in four patients with complete or partial damages of bladder. Two by cancer of bladder, one by traumatic delivery and the other by posthisterectomy.

Two patients with uretrovesicovaginal fistula (sewer) consulted by permanent outlet of urine by external genitals, their midde age was 22 years old and their socieconomical stratums were low. This patients had positive coulouring proofs and the citoscopy confirmed the presence of and extensive uretrovesicovaginal fistula with a large lose of tissue of bladder and tissue of vagina.

In all patients treated with Indiana's Surgery; it obtained sacs with fine capacity, low pressure and continence of urine with the use of catheters by themselves.

The contiguos and overdue postoperatives presented import morbility, that was resolute satisfactority.

The mortality ( 1 case) wasn't inherent to the surgery (cancer of bladder).

KEY WORDS: Incontinence of urine, Kock's sac, Mainz's sac, Indian'as sac for continence.

\section{Introducción}

En los últimos tiempos se ha notado un incremento progresivo por el uso de los reservorios urinarios continentes. Por ejemplo, el concepto de refacción del intestino para que pueda servir como reservorio urinario en lugar de la fabricación de un conducto, ha sido conocido universalmente debido a los trabajos realizados por Goodwing en 1958, mostrando ventajas sobre las cistoplastias de ampliación. La destrucción de la integridad peristáltica, y la remodelación intestinal de tal manera que las fuerzas peristálticas se anulen entre sí, han conducido al desarrollo de diversos reservorios continentes como: Bolsa de Kock, Bolsa de Mainz, y Reservorio continente de Indiana. Con ésta última técnica se consigue un reservorio con buena capacidad, baja presión, y continencia urinaria con autocateterización.

Estos nuevos métodos, proporcionan una calidad de vida superior ya que no requieren urostomía colectora.

\footnotetext{
* Docente Depto. de Urología.

** Docente Depto de Cirugía

*** Docente Depto de Ginecología

**** Residentes de Urología.
}

Así se evitan los problemas del estoma (inflamación, infección, estenosis) se elimina el olor a orina permanente, y las pérdidas ocasionales de las bolsas colectoras, con la consecuente incontinencia urinaria.

\section{Reservorio urinario continente de Indiana}

\section{Generalidades}

La idea de utilizar la válvula ileocecal reforzada como un mecanismo confiable de continencia que pudiera soportar el traumatismo producido por la cateterización intermitente fue propuesta por primera vez por Rowland y col. en la Universidad de Indiana (1987); esta modificación, junto con la abertura parcial del segmento cecal y la fijación del parche ideal, ha representado una importante contribución para mejorar el reservorio ileocecal descrito por Gilchirst (1950) en el que utilizaba el intestino intacto y no se efectuaba ninguna maniobra para reforzar la válvula ileocecal.

En su forma original el refuerzo de la válvula ileocecal consistía en una doble hilera de puntos invaginantes que se aplicaba sobre todo el segmento ileal.

Pronto se torna evidente que este paso era necesario sólo en la región de la válvula ileocecal. 
Los valores de presión alcanzado en la neouretra demostraron que la zona de continencia estaba confiada a la región de la válvula ileocecal remodelada.

La neouretra restante podía ser afinada y conducida a través de un estoma abdominal o perineal. En la Universidad de Indiana, así como en otras Instituciones, se considera que en algunos pacientes la marsupialización exclusiva peristáltica es suficiente como para contrarrestar el mecanismo de continencia.

\section{Cuidados postoperatorios}

\section{Comentarios}

El cuidado postoperatorio de los pacientes con la bolsa de Indiana o sus variantes no difiere mucho del que se utiliza en las otras bolsas cateterizables que utilizan el colon derecho.

Rowland recomienda que el paciente sea dado de alta del Hospital con el tubo de cecostomía todavía colocado. A las tres semanas el paciente vuelve a internarse para extraer el tubo y completar su instrucción en lo referente a la autocateterización.

El grupo de Indiana ha comunicado un promedio de capacidad de la bolsa de 400 a $500 \mathrm{ml}$; con la combinación de las técnicas con abertura intestinal parcial y total este grupo informa un índice de reintervenciones de $26 \%$, aunque los índices globales de continencia llegan a $93 \%$.

Carroll y Col. han realizado cuidadosos estudios urodinámicos en pacientes portadores de la bolsa de Indiana. Estos investigadores encontraron que sólo el 86\% de los pacientes habían alcanzado la continencia total en una serie numerosa.

Sin embargo, la capacidad de la bolsa excedió los 650 $\mathrm{ml}$. con contracciones pico de $47 \mathrm{~cm}$. de agua con relleno completo.

El grupo de la Universidad de Miami encontró continencia total en todos los pacientes de un pequeño grupo. Una obstrucción uretral fue tratada con dilatación con balón y no fue necesaria una reintervención. La capacidad media de la bolsa llegó a $750 \mathrm{ml}$ o más. Las presiones con relleno completo alcanzaron $20 \mathrm{cms}$ de agua. Ningún paciente necesitó un tratamiento con álcali.

\section{Objetivos}

\section{Generales}

Practicar en el paciente que lo amerite la Técnica quirúrgica de la Bolsa Continente de Indiana que le garantice una derivación y reservorio urinario, con atributos de una vejiga normal, evitando reflujos, incontinencia urinaria, y obstrucción de los uréteres.

\section{Específicos}

1. Brindar al paciente de la quinta o sexta década o aquellos de mayor edad con estado óptimo de salud portadores de un Ca. de vejiga urinaria, aún extirpables quirúrgicamente, la posibilidad de una mejor calidad de vida.

2. Mejorar el nivel de vida de pacientes con grandes fístulas ureterovesicovaginales secundarias a cirugías o partos traumáticos o instrumentados.

3. Seleccionar un grupo de pacientes con vejiga neurógena de difícil manejo que ameriten dicha técnica.

4. Analizar y establecer estadísticas propias con los resultados de la técnica quirúrgica en mención.

\section{Resultados}

Grupo pacientes con CA. de vejiga

1. En relación al sexo, los 2 casos se presentaron en hombres.

2. La edad media fue de 47 años.

3. En relación a su ocupación 1 era campesino (agricultor) otro era pintor.

4. Hábitos: los 2 eran fumadores.

5. Motivo de consulta: los 2 casos consultaron por hematuria como síntoma o signo dominante; adicionalmente 1 presentó irritabilidad vesical y 1 tenía micción pobre.

6. El diagnóstico se complementó en Consulta Externa con Urografía excretora, T.A.C., Cistoscopia + Bx. de la lesión.

A su hospitalización se les realizó examen o palpación bajo anestesia y Mapeo Vesical.

7. Hallazgos a la Cistoscopia: Lesión en cara lateral izquierda y trígono (1 paciente) y lesión en cara lateral derecha y trígono (1 paciente).

8. Técnica quirúrgica efectuada: Técnica Bolsa Continente de Indiana.

\section{Grupo fístulas uretrovesicovaginales}

1. Número de pacientes 2 (dos)

2. Sexo: Femenino

3. Edad media: 22 años.

4. Estrato socioeconómico bajo: 2 casos.

5. Antecedentes quirúrgicos y obstétricos:

Histerectomía abdominal total: 1 caso

Parto atendido por empírica: 1 caso.

6. Con relación al motivo de consulta los dos casos consultaron por salida de orina por genitales externos.

7. El diagnóstico se comprobó en consulta externa con Urografía excretora, cistoscopia, prueba del colorante que fue positiva en los dos casos.

8. Cirugía efectuada: Técnica Bolsa Continente de Indiana en los 2 casos.

\section{Complicaciones}

Para el análisis de las complicaciones se tomaron en conjunto los 4 casos sin individualizar cada grupo y se encontró:

1. Ileo paralítico al igual que cuadro febril, estuvieron presentes en los 4 casos.

2. Dos pacientes presentaron infección de la pared.

3. Síndrome de Dificultad respiratoria estuvo presente en 1 caso.

4. El cuadro de sepsis se presentó en 1 paciente.

5. Por último 1 paciente presentó vómitos y epigastralgia.

Las anteriores complicaciones fueron en el postoperatorio temprano.

En el postoperatorio Tardío (después de 4 meses):

1. Un paciente presentó eventración

2. Un paciente tuvo invasión a uretra por cáncer

3. Un paciente presentó priapismo

4. Sólo 1 paciente tuvo que ser reintervenido, puesto que presentó obstrucción mecánica por bridas.

En relación a la mortalidad, sólo hubo un fallecimiento (tardío) y se debió a metâstasis del Ca. de vejiga. 


\section{Conclusiones}

- De los cuatro pacientes, dos presentaron fístulas uretrovesicovaginales extensas.

- Dos casos presentaron CA. de vejiga en diversos estados según la clasificación de Marshall. Uno estaba en estado B y el otro en estado C.

- En el CA. de vejiga la palpación bimanual y el mapeo vesical clasificaron suficiente el tumor.

- Los pacientes se recuperaron satisfactoriamente en su postoperatorio.
- La histología predominante para los CA. de vejiga, fue CA. de células transicionales.

- Es importante corregir las deficiencias nutricionales, preparar bien el intestino, y administrar una buena alimentación, terapia antimicrobiana y respiratoria.

- El reservorio continente de Indiana ofrece el $100 \%$ de continencia para capacidad de 600 m.l. y autocateterismo 3 veces al día.

ANEXOS

Utilización del reservorio continente de Indiana en la patología del tracto urinario inferior

Tabla 1

METODOS DIAGNOSTICOS GRUPO PACIENTES CON CA. DE VEJIGA

\begin{tabular}{|l|l|l|}
\hline Diagnóstico & Estudio en C.E. & Hospitalizado \\
\hline $\begin{array}{l}\text { Carcinoma } \\
\text { de vejiga }\end{array}$ & $\begin{array}{l}\text { Urografía excretora } \\
\text { T.A.C. }\end{array}$ & $\begin{array}{l}\text { Palpación } \\
\text { Bajo anestesia } \\
\text { Cistoscopia+Biopsia }\end{array}$ \\
\begin{tabular}{l} 
Mapeo vesical \\
\hline
\end{tabular} \\
\hline
\end{tabular}

Tabla 2

HALLAZGOS GRUPO PACIENTES CON CA. DE VEJIGA

Hallazgos a las cistoscopia.

El compromiso de las partes fue:

\begin{tabular}{l|l}
\hline Cara lateral izquierda y trígono & 1 paciente \\
Cara lateral derecha y trígono & 1 paciente
\end{tabular}

\section{Tabla 3}

DIAGNOSTICO GRUPO PACIENTES CON FISTULA URETROVESICOVAGINAL

\begin{tabular}{|l|l|}
\hline Diagnóstico & Estudios de consulta externa \\
\hline $\begin{array}{l}\text { Fístula uretrovesico } \\
\text { vaginal extensa }\end{array}$ & $\begin{array}{l}\text { Urografía excretora } \\
\text { Cistoscopia } \\
\text { Prueba del colorante }\end{array}$ \\
\hline
\end{tabular}

Tabla 4

RESULTADOS PRUEBA DEL COLORANTE GRUPO PACIENTES CON FISTULA URETROVESICOVAGINAL

\section{Prueba del colorante}

Positiva 2 pacientes

Tabla 5

COMPLICACIONES POSTOPERATORIAS GRUPO PACIENTES CON CA. DE VEJIGA Y GRUPO PACIENTES CON FISTULA URETROVESICOVAGINAL

\begin{tabular}{|l|c|}
\hline Complicaciones & No. de Pacientes \\
\hline Ileo paralítico & 4 \\
Fiebre & 4 \\
Infección de la pared & 2 \\
Síndrome dificultad respiratoria & 1 \\
Sepsis & 1 \\
Vómitos + Epigastralgia & 1 \\
\hline
\end{tabular}

Tabla 6

COMPLICACIONES TARDIAS AMBOS GRUPOS

\begin{tabular}{|l|c|}
\hline Complicaciones tardías & (después de 4 meses) \\
\hline Eventración & 1 paciente \\
Invasión a uretra por cáncer & 1 paciente \\
Priapismo & 1 paciente \\
\hline
\end{tabular}

Tabla 7

REINTERVENCIONES AMBOS GRUPOS

\begin{tabular}{|l|}
\hline Reintervenciones \\
\hline Obstrucción mecánica por bridas 1 paciente \\
\hline
\end{tabular}

Tabla 8

MORTALIDAD AMBOS GRUPOS

\begin{tabular}{|l|}
\hline Mortalidad \\
\hline Por metástasis de Ca. de Vejiga 1 paciente \\
\hline
\end{tabular}

\section{BIBLIOGRAFIA}

1. Bricker EB. Bladder substitution after pelvic evisceration. Surgery Clinic N.A. 1950; 30-1511.

2. Gerber A. The Kock continent ileal reservoir for supravesical urinary diversion, and early experience Am. J. Surg. 1983; 146: 15.

3. Himman F. Selection of intestinal segments for bladder substitution phsical and physiological characteristic J. Urol. 1988; 139: 519.

4. Kock NG. Ileostomy withouth external applances, a survey of 25 patients provided with intrabdominal intestinal reservoir Am. Surg. $1971 ; 173-545$.
5. Rowland RG., Mitchell ME., Bihrle R. The cecoileal continent urinary reservoir worl. J. Urol. 1985; 9: 185.

6. Rowland RG., Mitchell ME., Bihrle R et al. The Indiana continent urinary reservoir. J. Urol. 1987; 137: 1136.

7. Skinner DG., Lieskovsky G., Boyd SD. Clinical experiences with the Kock continent ileal reservoir for urinary division. J. Urol. 1984; 132: 1101.

8. Skinner DG., Lieskovsky G., Boyd SD. Continuing experience with the continent ileal reservoir. J. Urol. 1987; 137: 1140. 